\title{
Comparison of SynCardia total artificial heart and HeartWare HVAD biventricular support for management of biventricular heart failure: a systematic review and meta-analysis
}

\author{
Elizabeth J. Maynes ${ }^{1}$, Thomas J. O'Malley ${ }^{1}$, Jessica G. Y. Luc ${ }^{2}$, Matthew P. Weber ${ }^{1}$, Dylan P. Horan ${ }^{1}$, \\ Jae Hwan Choi ${ }^{1}$, Sinal Patel ${ }^{1}$, Syed-Saif Abbas Rizvi ${ }^{1}$, Rohinton J. Morris ${ }^{1}$, John W. Entwistle ${ }^{1}$, \\ H. Todd Massey ${ }^{1}$, Vakhtang Tchantchaleishvili ${ }^{1}$ \\ ${ }^{1}$ Division of Cardiac Surgery, Thomas Jefferson University, Philadelphia, PA, USA; ${ }^{2}$ Division of Cardiovascular Surgery, Department of Surgery, \\ University of British Columbia, Vancouver, British Columbia, Canada \\ Correspondence to: Vakhtang Tchantchaleishvili, MD. Assistant Professor of Surgery, Division of Cardiac Surgery, Thomas Jefferson University, 1025 \\ Walnut St, Suite 607, Philadelphia, PA 19107, USA. Email: Vakhtang.Tchantchaleishvili@jefferson.edu.
}

Background: The aim of this study was to compare the outcomes of patients undergoing SynCardia total artificial heart (TAH) and biventricular HeartWare ventricular assist device (Bi-HVAD) support for biventricular heart failure $(\mathrm{HF})$.

Methods: Electronic search was performed to identify all relevant studies detailing patients who underwent biventricular assist device implantation using Bi-HVAD devices and those who underwent TAH placement for biventricular HF. Twelve studies including 512 patients in the TAH group versus 38 patients in the BiHVAD group were pooled for meta-analysis.

Results: Ischemic cardiac etiology was present in 32\% (95\% CI, 24-47) of TAH vs. 15\% (95\% CI, 4-44) of Bi-HVAD patients $(\mathrm{P}=0.21)$. There was a comparable incidence of stroke [TAH $11 \%(95 \% \mathrm{CI}, 7-16)$ vs. Bi-HVAD 13\% (95\% CI, 2-51), P=0.86] and acute kidney injury [TAH 28\% (95\% CI, 2-89) vs. Bi-HVAD $27 \%$ (95\% CI, 9-59), P=0.98]. Overall infection rate was 67\% (95\% CI, 47-82) in TAH and 36\% (95\% CI, 10-74) in Bi-HVAD ( $\mathrm{P}=0.16)$. Driveline infections were comparable between the two groups [TAH $11 \%$ (95\% CI, 6-19) vs. Bi-HVAD 8\% (95\% CI, 1-39), $\mathrm{P}=0.73$ ] and although a higher incidence of mediastinitis was found in the Bi-HVAD group [TAH 4\% (95\% CI, 2-7) vs. Bi-HVAD 15\% (95\% CI, 4-45), P=0.07] there was no statistically significant difference between the groups. Postoperative bleeding was present in $42 \%$ (95\% CI, 28-58) of TAH vs. $23 \%$ (95\% CI, 8-52) of Bi-HVAD (P=0.22). Patients in the TAH group had shorter duration of support [TAH 71 days (95\% CI, 15-127) vs. Bi-HVAD 167 days (95\% CI, 116-217), $\mathrm{P}=0.01]$. At the mean follow-up time of 120 days, (95\% CI, 83-157) patients in both groups had similar overall mortality [TAH 36\% (95\% CI, 22-49) vs. Bi-HVAD 26\% (95\% CI, 6-46), P=0.44] including mortality on device support [TAH 26\% (95\% CI, 17-36) vs. Bi-HVAD 21\% (95\% CI, 4-37), P=0.55]. Discharge home on support was achieved in $6 \%$ (95\% CI, 4-17\%) of TAH patients vs. $73 \%$ (95\% CI, 48-89\%) of Bi-HVAD ( $<<0.01)$, and 68\% (95\% CI, 52-84) of TAH patients were transplanted vs. 61\% (95\% CI, 47-75) in the Bi-HVAD group ( $\mathrm{P}=0.14)$.

Conclusions: Patients on Bi-HVAD support were more likely to be able to be discharged home on support and had similar overall mortality to TAH, albeit with much longer duration of support.

Keywords: Total artificial heart (TAH); biventricular heart failure; HeartWare HVAD

Submitted Feb 03, 2020. Accepted for publication Feb 28, 2020.

doi: 10.21037 /acs.2020.03.07

View this article at: http://dx.doi.org/10.21037/acs.2020.03.07

(c) Annals of Cardiothoracic Surgery. All rights reserved. 


\section{Introduction}

Recent United Network for Organ Sharing (UNOS) data demonstrate transplantation rates in the United States have hit all-time highs with 3,273 heart transplants performed in 2017 and 3,351 performed in 2019 (1). Despite this increase, a widening disparity exists between patients who need a transplant and those who receive one. Between 2006 and 2017, the number of patients on heart transplant waiting lists increased by approximately $49 \%$ from 2,424 to 3,623 (1). As the prevalence of heart failure (HF) grows in the aging American population, organ shortages are expected to grow by approximately $46 \%$ by 2030 . Given this discrepancy, continued improvements in HF prevention and management are necessary (2). While transplantation remains the best therapy for medically refractory end-stage biventricular HF, mechanical circulatory support (MCS) devices now offer an effective bridge-to-transplant option to treat patients awaiting organ transplantation and bridge this organ scarcity gap. While effective in many cases, up to $10 \%$ of patients on a continuous flow left ventricular assist device (CF-LVAD) develop biventricular failure requiring long-term additional right ventricular support (3).

Given the complexity of biventricular failure management, multiple solutions have been developed to attain the gold standard provided by transplantation. Among these, SynCardia's total artificial heart (TAH) has been the mainstay of mechanical support to replace both ventricles and all four heart valves as a bridge-to-transplant, with current destination therapy trials underway (4). With a proven record of effectiveness, the SynCardia TAH has been functioning as a biventricular failure option for over 20 years (5), and for now represents the only FDAapproved long-term biventricular replacement option. Despite this, there are many drawbacks to the device with respect to portability and ease of use at home. Clinicians are now experimenting with other therapies to provide care for patients with biventricular failure (6).

With demonstrated success for the treatment of left ventricular failure, CF-LVADs have emerged as a potential therapy option for those in biventricular failure. Clinicians have modified these devices in an off-label way to serve as an alternative to TAH $(7,8)$. Different pump combinations have been reported, the most common case being biventricular use of HeartWare HVAD pumps (6). Given its relatively smaller size compared to other devices in its class, the HVAD has often been chosen for biventricular failure patients as a two-device solution (6). Though its size places it at an advantage relative to other non-identical flow CFLVADs such as HeartMate II (HM2)/HeartWare HVAD (HeartWare Inc., Framingham, MA, USA), other device combinations have been attempted to treat biventricular failure, largely with mixed results (9). Despite this, some small series have reported successful use of a biventricular HeartWare HVAD in a select patient population. However, no studies have assessed the use of dual HVADs compared to TAH (6). Therefore, we performed this systematic review and meta-analysis to assess HeartWare HVAD biventricular support versus SynCardia TAH relative to perioperative and post-operative outcomes.

\section{Methods}

\section{Literature search strategy}

Studies reporting outcomes of SynCardia TAH implantation as well as HeartWare HVAD biventricular support were evaluated through an electronic search, performed in September 2018, using Ovid Medline, Embase, Cochrane Central Register of Controlled Trials (CCTR), Web of Science, Scopus and CINAHL. To achieve maximum sensitivity, we combined the terms: "heart-assist devices", "left ventricular assist device", "bridge to recovery", "device removal", "total artificial heart", "biventricular support" as either key words or MeSH terms. The reference lists of all retrieved articles were reviewed and assessed for further identification of potentially relevant studies.

\section{Selection criteria}

Eligible studies for the present systematic review and meta-analysis included those that discussed outcomes in biventricular HF patients who underwent biventricular assist device implantation using simultaneous right and left HeartWare HVAD (Bi-HVAD) devices and those that reported outcomes in patients who underwent SynCardia TAH replacement (TAH). We excluded TAH devices aside from the SynCardia TAH, and other biventricular CF-LVAD configurations aside from Bi-HVAD due to the limited number of these cases. By focusing solely on these two alternatives, we attempted to mitigate bias that would have introduced unnecessary noise in the data without any substantial increase in case numbers. When institutions published duplicate studies with overlapping individual patient data, only the most complete reports were included for quantitative assessment at each time 


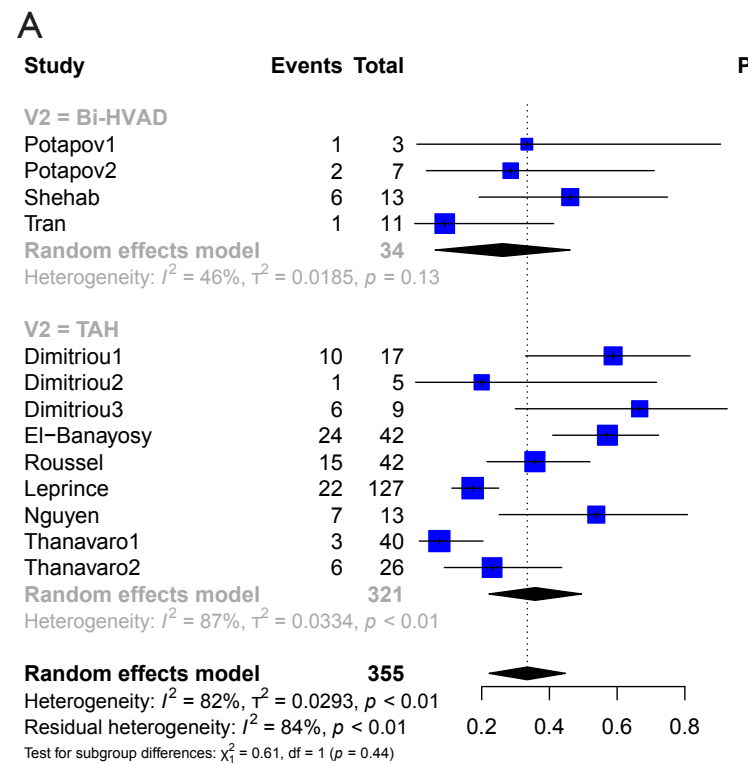

Proportion $\quad 95 \%-\mathrm{Cl}$ Weight

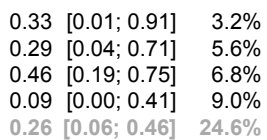

0.59 [0.33;0.82] $7.6 \%$ $0.20[0.01 ; 0.72] \quad 5.4 \%$ $0.67[0.30 ; 0.93] \quad 6.1 \%$ $0.57[0.41 ; 0.72] \quad 9.4 \%$ $0.36[0.22 ; 0.52] \quad 9.5 \%$ $0.17[0.11 ; 0.25] \quad 10.8 \%$ $0.54[0.25 ; 0.81] \quad 6.8 \%$ $0.08[0.02 ; 0.20] \quad 10.6 \%$ $0.23[0.09 ; 0.44] \quad 9.1 \%$ $0.36[0.22 ; 0.49] \quad 75.4 \%$

$0.33[0.22 ; 0.45] 100.0 \%$
B

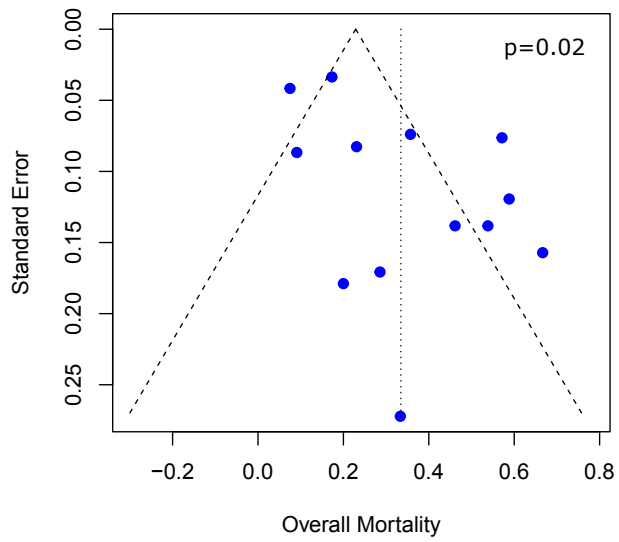

Figure 1 Overall mortality rate reported for patients who underwent TAH vs. Bi-HVAD implantation. (A) Forest plot demonstrating variable heterogeneity; (B) Egger's regression test and associated funnel plot to assess for publication bias. TAH, total artificial heart; BiHVAD, biventricular HeartWare ventricular assist device.

interval. All publications were limited to the English language and published since 2000. A risk of bias assessment was performed using the Newcastle-Ottawa Scale (NOS) scoring which can be found in Table S1. A full list of studies included in the analysis can be seen in Table $S 2$.

\section{Data extraction}

All data were extracted from article texts, tables, and figures by one reviewer (JHC). When data was not available, attempts were made to contact corresponding authors to obtain the relevant data for the current study.

\section{Statistical analysis}

Baseline characteristics, demographics, and outcomes were reported as the pooled mean and $95 \%$ confidence intervals (CI). Dichotomous variables between the groups were compared using meta-analysis of proportions with logit transformation, while continuous variables were compared using meta-analysis with a random-effects model. Heterogeneity was evaluated using Cochran Q and $\mathrm{I}^{2}$ statistic. Egger's regression test for funnel plot asymmetry was performed to assess for publication bias (Figures 1-3). All analyses were performed with $\mathrm{R}$ software 3.5.0, meta package (R Foundation for Statistical Computing, Vienna, Austria).
$\mathrm{P}$ values $<0.05$ were considered statistically significant.

\section{Results}

\section{Study characteristics}

A total of 2,584 records were identified in the literature search. Following application of the inclusion and exclusion criteria, 12 studies comprising 550 patients were pooled for analysis. A total of 512 (93\%) patients underwent TAH implantation and 38 (6\%) patients underwent Bi-HVAD implantation. A PRISMA flow diagram depicting the overall search strategy is shown in Figure 4. A manual search of references did not yield additional studies.

\section{Patient characteristics}

Baseline patient characteristics are shown in Table 1. In comparing between patients who received TAH and BiHVAD, there were no significant differences in patient age [TAH 54.2 (95\% CI, 48.2-60.3) vs. Bi-HVAD: 54.3 (48.160.4), $\mathrm{P}=0.99$ ] with $86 \%$ [83-89] of patients being male. In addition, there was no significant difference in the number of patients with ischemic etiologies for biventricular HF (31\%; 95\% CI, 23-40) between the TAH and Bi-HVAD groups [TAH 32\% (95\% CI, 24-47) vs. Bi-HVAD 15\% (95\% CI, 
A

Study

V2 = BiVAD

Potapov1

Potapov2

Maltais

Shehab

Tran

Random effects model

Heterogeneity: $I^{2}=42 \%, T^{2}=0.0148, p=0.14$

$\mathrm{V} 2=\mathrm{TAH}$

El-Banayosy

Kirsch

Roussel

Leprince

Nguyen

Copeland

Thanavaro1

Thanavaro2

Random effects model

Heterogeneity: $I^{2}=82 \%, T^{2}$

Random effects model

$\begin{array}{llllll}\text { Heterogeneity: } I^{2}=74 \%, T^{2}=0.0127, p<0 & & & \mid & \\ \text { Residual heterogeneity: } I^{2}=76 \%, p<0.010 & 0.2 & 0.4 & 0.6 & 0.8\end{array}$

Test for $x^{2}=0.35, \mathrm{df}=1(p=0.55)$
Events Total

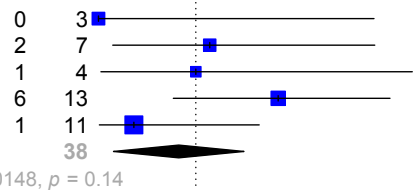

Proportion

$95 \%-\mathrm{Cl}$ Weight
B

Figure 2 Mortality on device support reported for patients who underwent TAH vs. Bi-HVAD implantation. (A) Forest plot demonstrating variable heterogeneity; (B) Egger's regression test and associated funnel plot to assess for publication bias. TAH, total artificial heart; BiHVAD, biventricular HeartWare ventricular assist device.

A

Study

Events Total

V2 = BiVAD

Potapov2

Maltais

Shehab

Tran

Random effects model

Heterogeneity: $I^{2}=67 \%, T^{2}=0.0458, p=0.03$

$\mathrm{V} 2=\mathrm{TAH}$

El-Banayosy

Kirsch

Roussel

Nguyen

Copeland

Thanavaro1

Thanavaro2

Random effects model

Heterogeneity: $I^{2}=92 \%, T^{2}=0.0403, p<0.01$

Random effects model

Heterogeneity: $I^{2}=90 \%, T^{2}=0.0460, p<0.01$

Residual heterogeneity: $I^{2}=89 \%, p<0.01$

Test for subgroup differences: $\mathrm{X}_{1}^{2}=2.14, \mathrm{df}=1(p=0.14)$

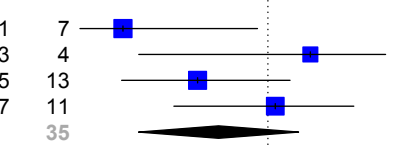

Proportion $\quad 95 \%-\mathrm{Cl}$ Weight

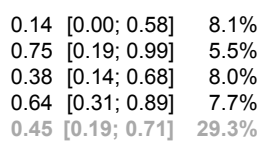

$0.26[0.14 ; 0.42] \quad 10.2 \%$

$0.63[0.53 ; 0.73] \quad 10.6 \%$

$0.71[0.55 ; 0.84] \quad 10.1 \%$

$0.77[0.46 ; 0.95] \quad 8.6 \%$

$0.68[0.58 ; 0.77] \quad 10.7 \%$

$0.92[0.80 ; 0.98] 10.8 \%$

$0.77[0.56 ; 0.91] \quad 9.7 \%$

$0.68[0.52 ; 0.84] \quad 70.7 \%$

$0.61[0.47 ; 0.75] 100.0 \%$
B

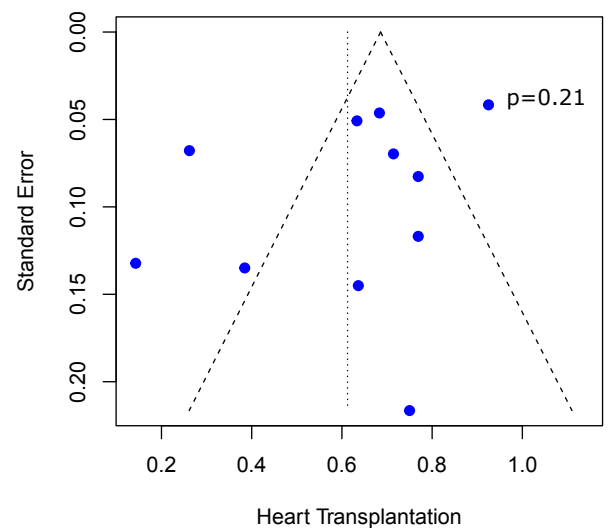

Figure 3 Heart transplantation rates reported for patients who underwent TAH vs. Bi-HVAD implantation. (A) Forest plot demonstrating variable heterogeneity; (B) Egger's regression test and associated funnel plot to assess for publication bias. TAH, total artificial heart; BiHVAD, biventricular HeartWare ventricular assist device.

4-44), $\mathrm{P}=0.21]$. Patients in the TAH group had a higher baseline preoperative cardiac index (CI) [TAH 1.9 (IQR, 1.5-2.3) vs. Bi-HVAD 1.4 (IQR, 1.0-1.7), $\mathrm{P}=0.05]$; however, there was no statistically significant difference in intra-aortic balloon pump use in the TAH group [TAH 47\% (95\% CI,
25-70) vs. Bi-HVAD 22\% (95\% CI, 10-41), $\mathrm{P}=0.09]$.

Further, those with TAH were more likely to have prior cardiac surgery [TAH 44\% (95\% CI, 28-62) vs. Bi-HVAD $8 \%$ (95\% CI, 1-39), $\mathrm{P}=0.04]$. Patients in the Bi-HVAD group were more likely to have been previously supported 

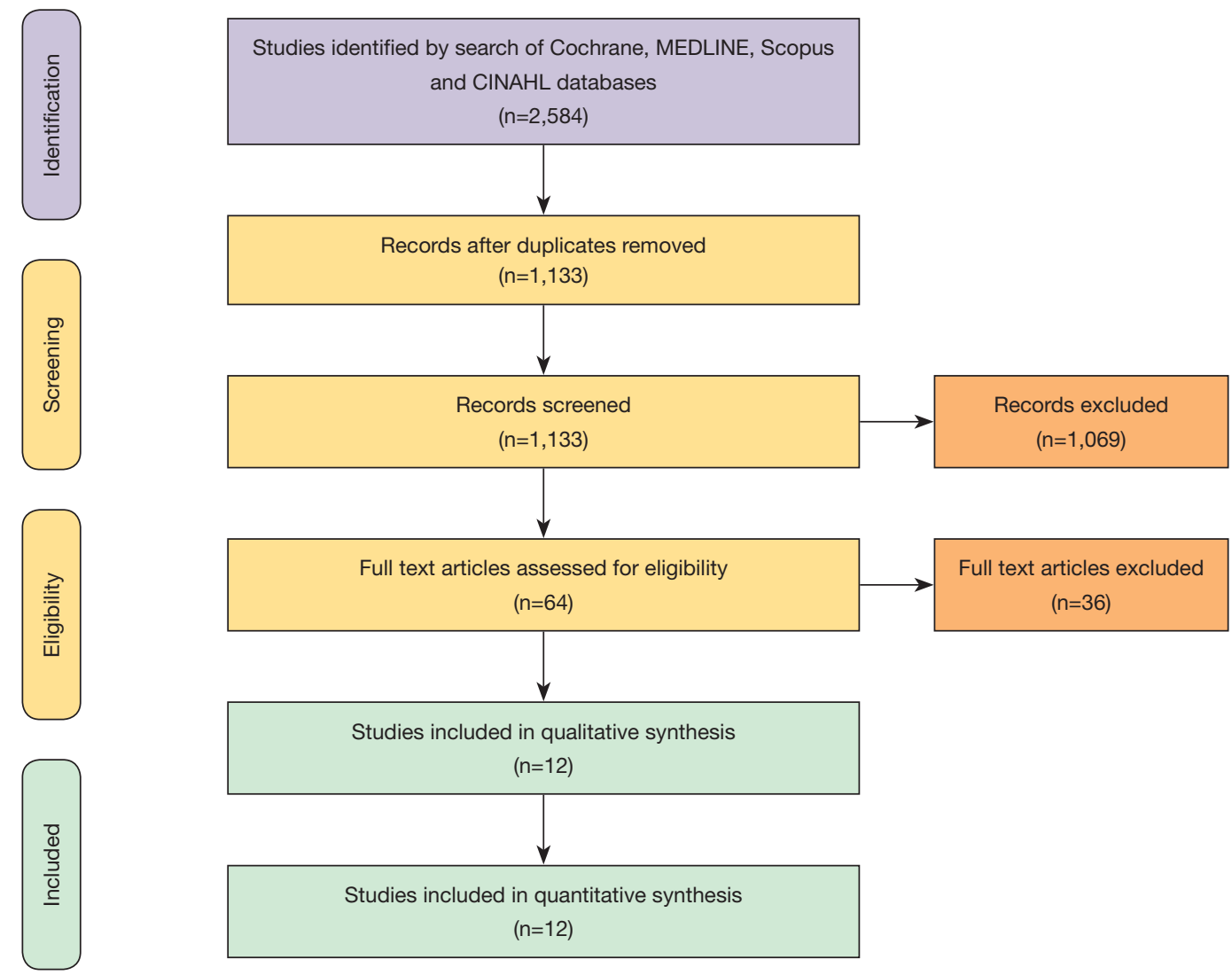

Figure 4 PRISMA schematic diagram of the search strategy. PRISMA, Preferred Reporting Items for Systematic Reviews and MetaAnalysis.

on extracorporeal membrane oxygenation support (ECMO) [TAH 10\% (95\% CI, 4-26) vs. Bi-HVAD 36\% (95\% CI, 1760), $\mathrm{P}=0.04]$. There were no differences between the groups in terms of rates of prior durable MCS [TAH 10\% (95\% CI, 5-20) vs. Bi-HVAD 13\% (95\% CI, 4-35), $\mathrm{P}=0.68$ ]. All other baseline characteristics were comparable including body mass index (BMI), preoperative liver and kidney function as well as hemodynamic function including pulmonary artery pressure (PAP) and inotropic support. There were no differences in Interagency Registry for Mechanically Assisted Circulatory Support (INTERMACS) profile with the majority of patients being INTERMACS I (60\%; 95\% CI, 39-78) and INTERMACS II (28\%; 95\% CI, 10-58).

\section{Perioperative details}

No difference in overall infection rate was observed between the two groups [TAH 67\% (95\% CI, 46-82) vs. Bi-HVAD $36 \%$ (95\% CI, 10-74), $\mathrm{P}=0.16]$ and no difference was noted for driveline infections [TAH 11\% (95\% CI, 6-18) vs. Bi-HVAD 8\% (95\% CI, 1-39), $\mathrm{P}=0.73$ ]. While patients with Bi-HVAD were more likely to develop mediastinitis [TAH 4\% (95\% CI, 2-7) vs. Bi-HVAD 15\% (95\% CI, 4-45), $\mathrm{P}=0.07$ ], there was no statistically significant difference between these groups. Furthermore, there were no differences in rates of stroke or need for cardiac reoperations between the two groups. Other perioperative and postoperative complications such as, gastrointestinal (GI) bleeds, neurological events, stroke, acute kidney injury, were comparable between both groups (Table 2).

\section{Post-operative outcomes and survival}

Patients with Bi-HVAD were more likely to be discharged on device support [TAH 6\% (95\% CI, 4-17) vs. Bi-HVAD $73 \%$ (95\% CI, 48-89), $\mathrm{P}<0.01]$. However, patients in the TAH group had shorter overall duration of support [TAH 71 days (95\% CI, 15-127) vs. Bi-HVAD 167 days (95\% 


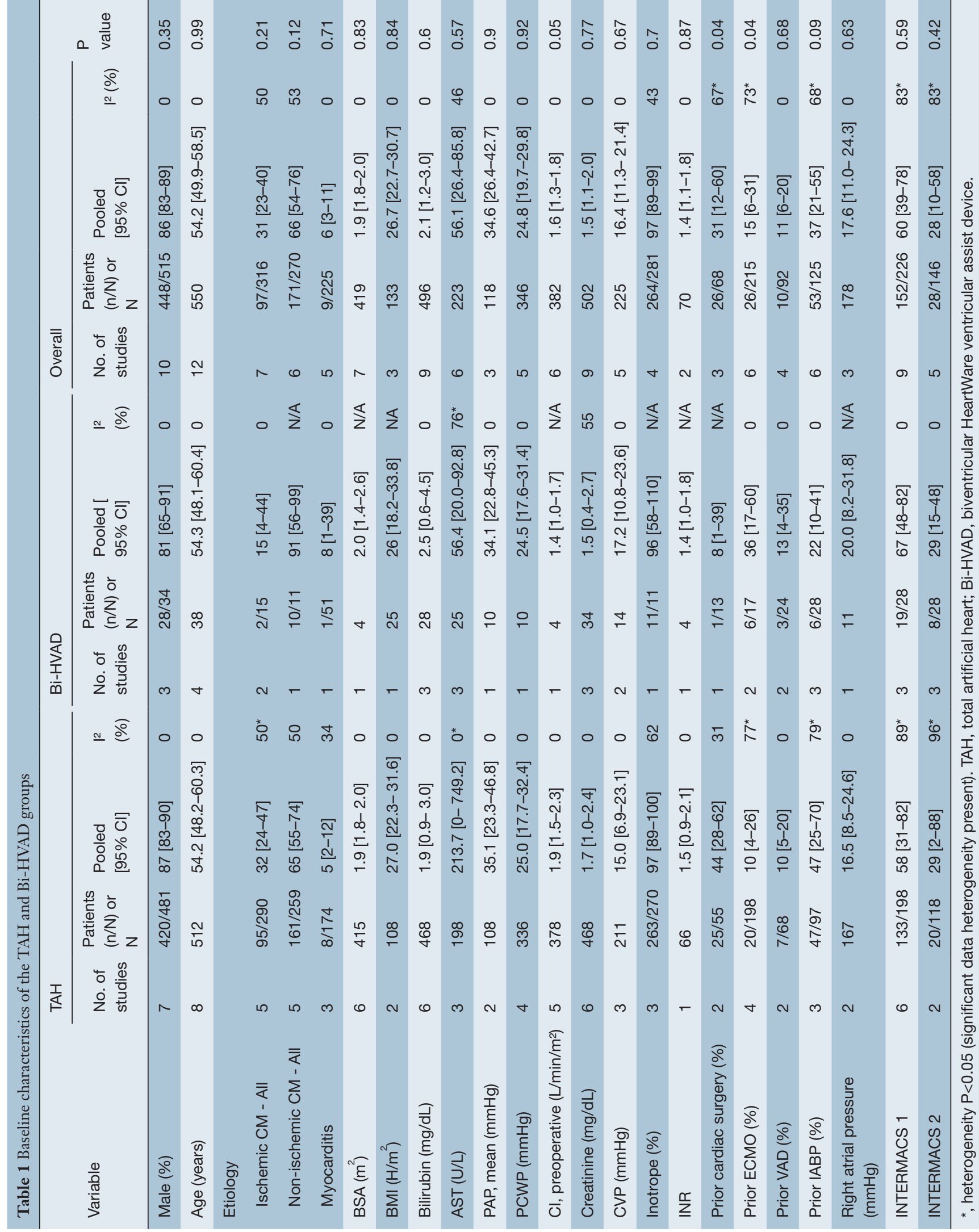




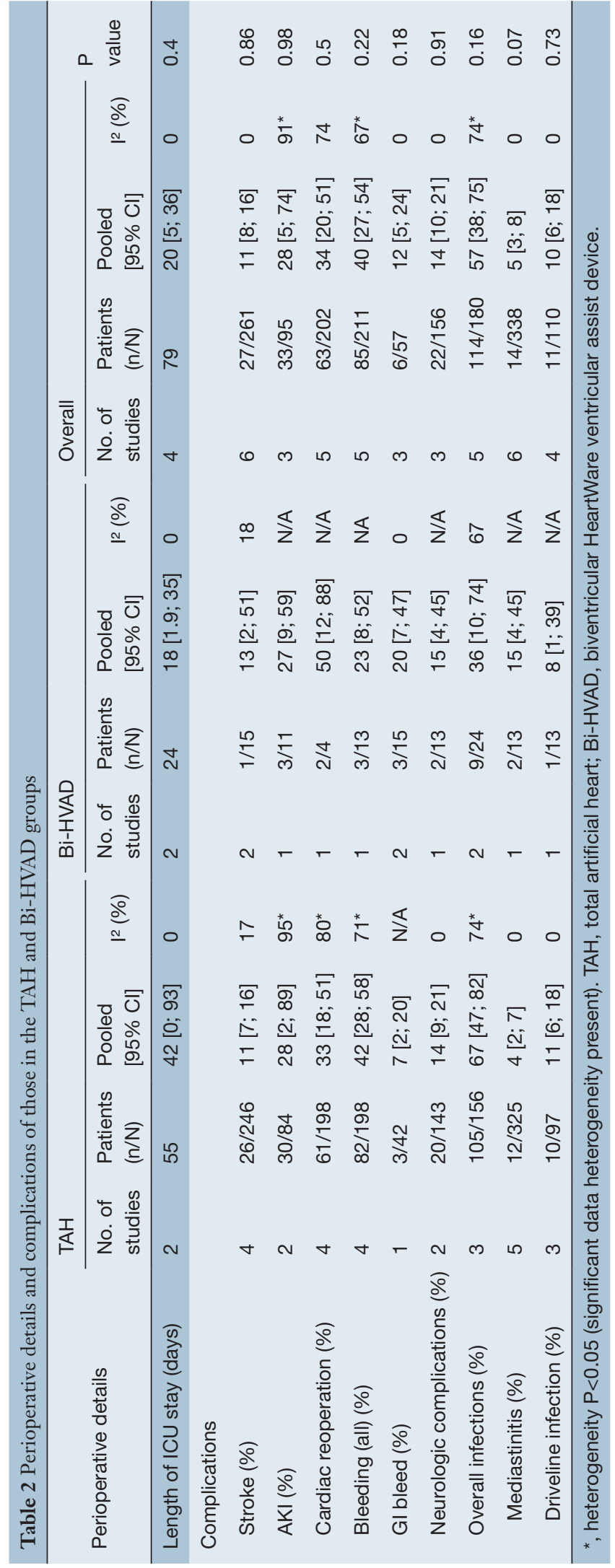

CI, 116-217), $\mathrm{P}=0.01]$. There was a similar rate of use as a bridge to heart transplantation [TAH 68\% (95\% CI, 52 84) vs. $61 \%$ (95\% CI, 47-75), $\mathrm{P}=0.14]$ with no significant difference between the groups. The overall mortality rate was high for both groups at a median follow-up time of 4 months [TAH 36\% (95\% CI, 22-49) vs. Bi-HVAD 26\% (95\% CI, 6-46), $\mathrm{P}=0.44]$. The majority of deaths were on device support [TAH 26\% (95\% CI, 17-36) vs. Bi-HVAD $21 \%$ (95\% CI, 4-37), P=0.55]. Causes of death included multi-organ failure which was especially high in the BiHVAD group [TAH 15\% (95\% CI, 5-35) vs. Bi-HVAD $23 \%$ (95\% CI, 8-52), P<0.01], sepsis [TAH 7\% (95\% CI, 4-12) vs. Bi-HVAD 19\% (95\% CI, 6-46), $\mathrm{P}=0.12]$ or intracranial hemorrhage [TAH 3\% (95\% CI, 1-7) vs. BiHVAD 10\% (95\% CI, 3-27), P=0.09]. Clinical outcomes are shown in Table 3.

\section{Discussion}

The evolution and improvement of MCS has led to multiple solutions outside of transplantation to devastating problems like biventricular failure. The two systems noted here, TAH and $\mathrm{Bi}-\mathrm{HVAD}$, each represent viable management options for patients with severe biventricular HF but possess their own set of advantages and disadvantages clinicians should be cognizant of when making a biventricular support system choice. Several key differences exist between the TAH versus Bi-HVAD groups found in this study. Specifically, we noted that while more patients with a TAH developed infections following device implantation, mediastinitis was significantly more prevalent in the Bi-HVAD group. Additionally, we noted a higher rate of bleeding in the TAH group when compared to the Bi-HVAD group. Finally, we found a shorter duration of support in the TAH group and significantly higher rate of hospital discharge on support among the Bi-HVAD group.

Two other studies have focused on the topic of BiVAD for biventricular support. Arabía et al. performed a recent INTERMACS study (5) evaluating this patient population while Cheng et al. also performed a UNOS registry study concerning this topic. These two studies and ours differ with respect to specific inclusion of criteria. Arabía et al. focused on all continuous flow devices that were used in a BiVAD configuration in the registry, while Cheng et al. included all types of biventricular MCS including pulsatile solutions. Our study focused only on the use of durable BiHVAD. While all three studies generally share similar preoperative characteristics among patient groups, they differ 


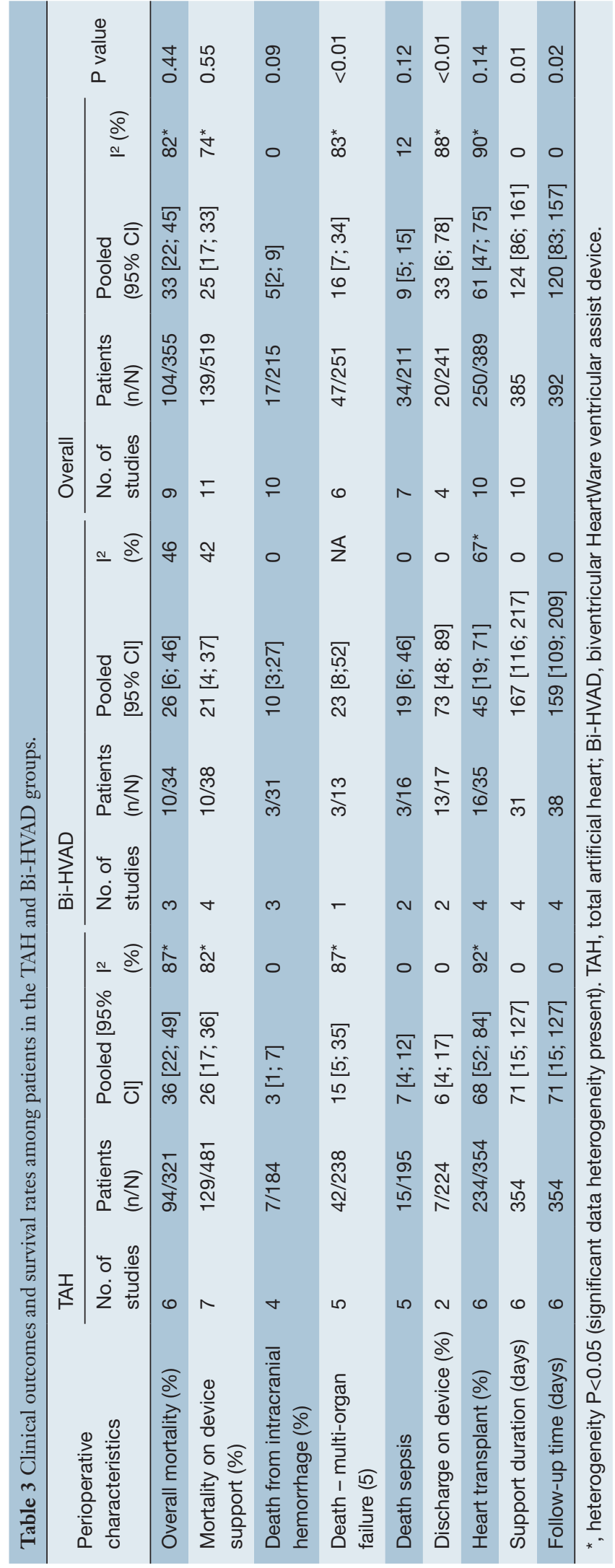

slightly in post-operative outcomes. These differences can likely be explained by the inclusion of different devices in the treatment groups of each study. We limited our inclusion criteria to Bi-HVAD in order to approach the true results of this particular device configuration and limit the effect of other less commonly used configurations on our results.

Previous studies examining outcomes for TAH and BiHVAD have been discussed independently in the literature, yet these are mostly as single center studies and case reports. In an attempt to obtain more robust data and conclusions, Cheng et al.'s UNOS database analysis identified over 17,000 adult patients undergoing heart transplantation who were supported on various models of either TAH or various different configurations of biventricular assist devices (10). While this earlier study highlighted several key differences between these two groups, there are important distinctions to make which limit the interpretation of their results in a modern biventricular failure cohort. One important limitation to a database study of this kind is the lack of differentiation between pulsatile and continuous flow devices. By including various different biventricular devices, a more heterogenous cohort is encountered for the biventricular support (BiVAD) group and therefore limits the strength and generalizability of their conclusions. Cheng et al. included patients on older generation pulsatile devices such as paracorporeal pVAD (Abbott, Pleasanton, CA, USA), Abbott implantable iVAD (Abbott), Heartmate II LVAD (Abbott) along with HVAD devices (10). Further, given data based on the UNOS database, many complications such as bleeding, pump thrombosis, arrhythmia, and stroke rate, could not be not reported or compared within the groups. The inability to compare complications and outcomes between devices further limits conclusions able to be drawn from this study.

When comparing baseline and device characteristics between this UNOS database study and ours, important distinctions can be made regarding patients with TAH and on BiVAD. Cheng et al. demonstrated a significantly lower BMI and lower mean PAP among the BiVAD group. Further, they demonstrated a significantly higher creatinine in the TAH group, suggesting a significantly higher rate of renal failure among these patients. This difference was not significant in our study. However, it has been previously noted that patients on TAH experience renal failure as impaired perfusion and bleeding can lead to end-organ dysfunction and failure (11).

Following sub-total cardiectomies and implantation of 
$\mathrm{TAH}$, there is an abrupt withdrawal of B-type natriuretic peptide (BNP) that can lead to impaired renal function (13). This is further supported as the infusion of exogenous BNP after implantation of TAH has been shown to improve renal function (13). One recent study has also investigated infusion of nesiritide, a BNP analogue, after implantation of the TAH and showed that this can help decrease the need for kidney transplantation (14). While no significant difference was found between the two groups in our study, patients in the TAH and Bi-HVAD groups had baseline creatinine levels suggestive of baseline kidney disease and/or pre-existing injury (1.7 and 1.5 , respectively, $\mathrm{P}=0.77$ ), and the incidence of postoperative acute kidney injury was also comparable between the groups [28\% (95\% CI, 2-89) TAH vs. 27\% (95\% CI, 9-59) Bi-HVAD, $\mathrm{P}=0.98]$. For the Cheng et al. study, which noted that higher post-operative creatinine was associated with lower transplant survival, these values were 1.7 and 1.3 , respectively for the TAH and BiVAD groups $(\mathrm{P}<0.0001)$.

Despite some differences, there were some notable similarities between our study and Cheng et al. Both studies found no significant difference in terms of survival on the waitlist or while on support. Additionally, while both groups showed a higher overall survival of patients on Bi-VAD, our study demonstrated a longer time on support in the BiHVAD ( $\mathrm{P}=0.01)$ group. However, given Bi-HVAD had a comparable overall mortality rate to TAH (TAH, 36\% vs. Bi-HVAD, 25\%; $\mathrm{P}=0.44$ ) with a longer time on support, this may suggest superior survival at similar follow-up.

When examining duration of support in the TAH group when compared to the Bi-HVAD group, our study demonstrates a lower duration of support with TAH while Cheng et al. showed a significantly lower time on waitlist among the Bi-VAD group. This difference is likely explained by the use of older generation VADs which were included in the UNOS database study. Devices in Cheng et al., such as the biventricular Abbott paracorporeal pVAD, and Abbott implantable iVAD are known for their limitations in terms of long-term durable support. Results have shown that the median support duration was 34 (range, 0-385) days for paracorporeal pVADs (15). By including older devices, these lower duration of support and lower time on waitlist differences are likely reflected.

Long-term support on HeartWare devices for left-sided support has been reported extensively in the literature which may help explain the longer time on dual devices found in our study. Aaronson et al. presented outcomes of patients who have been supported by the HVAD system for more than 2 years; in the HeartWare BTT and continued access protocol trial, 74 of 382 total patients (19.4\%) had more than 2 years and many of these patients were maintained effectively through 3 years of support duration (16). Increased duration of support within the Bi-HVAD group is also attainable since devices may be exchanged or upgraded when technical problems arise or when patients develop extensive complications. Combined time on the initial and replacement HVAD devices can increase support duration substantially, unlike the TAH which cannot be exchanged. One more recent study demonstrated how 30 patients placed on CF-LVAD for destination therapy underwent 35 replacement procedures which helped to extend their support duration (17).

Another notable finding in the current study was that patients in the Bi-HVAD group were also more likely to be discharged from the hospital. Both HVAD systems run quietly, and although patients generally need to carry two controllers and up to four batteries, they experience a higher grade of freedom and mobility (16). This increased freedom and mobility may suggest why patients on BiHVAD are more likely to be discharged from the hospital. Contrary to the Bi-HVAD systems, the TAH was attached to a bulkier console that substantially impeded patient mobility. Around 2004, a novel portable pneumatic driver had been developed to allow better patient mobility and independence leading to patient discharge following stabilization on TAH. Although this aided mobility to a certain degree, the portable driver remained about the size of a briefcase and had to be dragged (18). The development of the Portable Freedom Driver for the TAH has enabled discharge while awaiting transplant, potentially allowing increased TAH support outside the hospital (17).

Currently, the TAH system requires more technical support which can keep the patient in the hospital longer than anticipated as the complication rates and need for patient monitoring associated with the device can limit the extent to which patients are afforded the freedom to leave the hospital. In particular, hemorrhage remains a major limitation as a result of extensive antithrombotic therapy necessary for patients on the devices with bleeding rates and neurological complications requiring intervention remaining high (19). Although the difference was not significant, there was a higher overall infection rate in the TAH group though mediastinitis was significantly higher in the Bi-HVAD group. One reported series documented the occurrence of infections in patients with TAH and found that the incidence of infections was extremely high 
with the most common locations of infection in the urinary tract, the respiratory tract, and the bloodstream, with many patients having multiple infections (20). Given the entire native heart and proximal portions of the great arteries are excised with TAH implantation the distinction between endocarditis, pericarditis, and mediastinitis is difficult to assess in this patient population (20). The relatively higher rate of mediastinitis in the Bi-HVAD group perhaps reflects the risk of postoperative mediastinitis that has been seen in patients following isolated CF-LVAD implant surgeries. Multiple surgeries are often required following CF-LVAD implantation (21) including exchange procedures which can be associated with high rates of infection and infection relapse. Mediastinitis is understood to be one of the most common complications associated with long-term durable support and despite aggressive treatment, the mortality rate can be high in those who develop it (22).

In addition to the infection risk of TAH, rates of overall bleeding were also higher in the TAH group in our study when compared to the Bi-HVAD group. Hermen et al. showed that TAH patients are at risk for delayed postoperative bleeding, due to pulsatility of the TAH and high $\mathrm{dP} / \mathrm{dT}$; therefore, it has been suggested that bleeding from the aortic anastomosis should be considered in the differential of a patient with low flow and/or tamponade (23). In a study by Copeland et al., authors assessed consistent anticoagulation protocols in 99 consecutive patients and observed post-implantation bleeding in $20 \%$. All but two were within the first postoperative week (24).

One additional caveat to the TAH versus Bi-VAD comparison is the recent designation of TAH patients to Status 2 according the UNOS allocation policy (9). This reflects the complex milieu within which patients on MCS are now designated. Under the previous system, Status 1A patients were classified as having life expectancies of less than 7 days if they did not receive a heart transplant and if they were not managed effectively with medication or MCS. The next most urgent category was Status 1B; these patients were those on ventricular assist devices for at least 30 days or who had been administered continuous IV inotropes. For Status 1B candidates, $12 \%$ to $34 \%$ received transplants between 30 and 90 days, respectively, of being actively listed as a transplant candidate. The remaining patients $(21.9 \%)$, who were actively listed waited at least 2 years for a donor heart $(25,26)$.

In contrast, the previous allocation system was the 3-tier system (Status 1A, 1B and 2) which has evolved to a 7-tier system (Status 1-6) as of September 2018. Status 2 patients now include those who cannot be discharged from the hospital such as TAH patients, those with surgically placed CF-LVADs or BiVADs and those on intra-aortic balloon pumps (5). The more refined system also allows for greater distinctions between the different types of MCS devices, such as the differentiation between temporary or durable devices (27). One main alteration to the new system was the breakdown of $1 \mathrm{~A}$ into three separately ranked categories (1, 2 and 3). Since TAH patients have become a higher status within this new system, it can be assumed that waiting list mortalities will likely decrease in the future since they will be transplanted sooner. This new designation system and the decision-making that has resulted from it may also help to explain the shorter duration of support among those on TAH (28).

While the mortality rates in the current study were comparable between the TAH and Bi-HVAD groups, death from multi-organ failure in the TAH group was significantly lower when compared to the Bi-HVAD group. This may be explained by the well-known end-organ recovery associated with the TAH management compared to other ventricular assist devices (29). For example, TAH is understood to address many of the problems seen in bridge to transplantation with left ventricular and biventricular assist devices, such as right HF, low blood flow, valvular regurgitation, cardiac arrhythmias, intraventricular communications and ventricular clots (29).

For patients with medically refractory end-stage biventricular HF, heart transplant continues to be the best long-term treatment. However, both Bi-HVAD and TAH can be considered acceptable bridge to transplant options. For this study, the heart transplantation rates were comparable between the two groups with an overall transplantation rate of $61 \%$. TAH has been the traditional option for bridge to transplant in those with severe biventricular failure but as newer Bi-VAD configurations are being adopted and acceptable outcomes are being reported, more patient-specific options are now available. More research is needed to assess patient outcomes following treatment with TAH and Bi-HVAD support.

\section{Limitations and future directions}

This meta-analysis has several key limitations and must be interpreted with care. Differences existed in patient selection for various procedures and in the comparative analysis, the number patients in the Bi-HVAD group was smaller due to a limited number of studies and due to 
the novelty of dual HVAD use for biventricular failure. Some heterogeneity in our study populations was evident, however, we attempted mitigate this problem by including studies on SynCardia TAH and HVAD devices only. Statistical testing was performed as recommend by the Cochrane Collaboration as a way to quantify publication bias and to show that bias occurred at acceptable rates; however multiple testing limitations may have increased the likelihood of type 1 errors.

\section{Conclusions}

Patients on Bi-HVAD support were more likely to be discharged home on support but had similar overall mortality to TAH, albeit a much longer duration of support.

\section{Acknowledgments}

None.

\section{Footnote}

Conflicts of Interest: The authors have no conflicts of interest to declare.

\section{References}

1. UNOS - Transplant trends. Available online: https://unos. org/data/transplant-trends/

2. Jackson SL, Tong X, King RJ, et al. National Burden of Heart Failure Events in the United States, 2006 to 2014. Circ Hear Fail [Internet]. 2018. Available online: https://www.ahajournals.org/doi/10.1161/ CIRCHEARTFAILURE.117.004873

3. Kirklin JK, Naftel DC, Kormos RL, et al. Fifth INTERMACS annual report: risk factor analysis from more than 6,000 mechanical circulatory support patients. J Heart Lung Transplant 2013;32:141-56.

4. SynCardia 70cc TAH-t for Destination Therapy (DT) (RA-540). Available online: https://clinicaltrials.gov/ct2/ show/NCT02232659

5. Arabía FA. SynCardia total artificial heart opportunities and challenges moving forward. Artif Organs 2019;43:1051-2.

6. Shehab S, Macdonald PS, Keogh AM, et al. Long-term biventricular HeartWare ventricular assist device support-Case series of right atrial and right ventricular implantation outcomes. J Heart Lung Transplant 2016;35:466-73.
7. Saito S, Sakaguchi T, Miyagawa S, et al. Biventricular support using implantable continuous-flow ventricular assist devices. J Heart Lung Transplant 2011;30:475-8.

8. Tsukui H, Teuteberg JJ, Murali S, et al. Biventricular assist device utilization for patients with morbid congestive heart failure: a justifiable strategy. Circulation 2005;112:I65-72.

9. Baldwin ACW, Sandoval E, Cohn WE, et al. Nonidentical Continuous-Flow Devices For Biventricular Support. Tex Heart Inst J 2017;44:141-3.

10. Cheng A, Trivedi JR, Van Berkel VH, et al. Comparison of total artificial heart and biventricular assist device support as bridge-to-transplantation. J Card Surg 2016;31:648-53.

11. Nesiritide and Renal Function After the Total Artificial Heart. Available online: https://clinicaltrials.gov/ct2/show/ NCT01836809

12. Arabía FA, Milano CA, Mahr C, et al. Biventricular Support With Intracorporeal, Continuous Flow, Centrifugal Ventricular Assist Devices. Ann Thorac Surg 2018;105:548-55.

13. Delgado R 3rd, Wadia Y, Kar B, et al. Role of B-type natriuretic peptide and effect of nesiritide after total cardiac replacement with the AbioCor total artificial heart. J Heart Lung Transplant 2005;24:1166-70.

14. Shah KB, Kalya AV, Hassanein MT, et al. Infusion of Nesiritide after Implantation of the Total Artificial Heart Is Associated with Decreased Need for Kidney Transplantation. J Hear Lung Transplant 2014;33:S61.

15. Sponga S, Benedetti G, Livi U. Short-term mechanical circulatory support as bridge to heart transplantation: paracorporeal ventricular assist device as alternative to extracorporeal life support. Ann Cardiothorac Surg 2019;8:143-50.

16. Aaronson KD, Silvestry SC, Maltais S, et al. Patients Awaiting Heart Transplantation on HVAD Support for Greater Than 2 Years. ASAIO J 2016;62:384-9.

17. Schechter MA, Daneshmand MA, Patel CB, et al. Outcomes After Implantable Left Ventricular Assist Device Replacement Procedures. ASAIO J 2014;60:44-8.

18. Samak M, Fatullayev J, Sabashnikov A, et al. Past and Present of Total Artificial Heart Therapy: A Success Story. Med Sci Monit Basic Res 2015;21:183-90.

19. Khan Minhas AM. Total Artificial Heart as the Destination Therapy: A Review. Am J Cardiovasc Thorac Surg 2017;2:1-6.

20. Hidalgo LF, Shah KB, Cooke RH, et al. Infections in Patients with a Total Artificial Heart Are Common but Rarely Fatal. ASAIO J 2017;63:736-9.

21. Pieri M, Müller M, Scandroglio AM, et al. Surgical 
Treatment of Mediastinitis with Omentoplasty in Ventricular Assist Device Patients. ASAIO J 2016;62:666-70.

22. Kretlow J, Izaddoost SA, Ho J, et al. Use of Antibiotic Beads in the Treatment of Left Ventricular Assist Device Infections. J Hear Lung Transplant 2013;32:S276.

23. Hermsen JL, Smith JW, Pal JD, et al. Late Surgical Bleeding Following Total Artificial Heart Implantation. J Card Surg 2015;30:771-4.

24. Copeland J, Copeland H, Nolan P, et al. Results with an Anticoagulation Protocol in 99 SynCardia Total Artificial Heart Recipients. ASAIO J 2013;59:216-20.

25. Nicholson C, Paz JC. Total artificial heart and physical therapy management. Cardiopulm Phys Ther J

Cite this article as: Maynes EJ, O’Malley TJ, Luc JGY, Weber MP, Horan DP, Choi JH, Patel S, Abbas Rizvi SS, Morris RJ, Entwistle JW, Massey HT, Tchantchaleishvili V. Comparison of SynCardia total artificial heart and HeartWare HVAD biventricular support for management of biventricular heart failure: a systematic review and meta-analysis. Ann Cardiothorac Surg 2020;9(2):69-80. doi: 10.21037/acs.2020.03.07
2010;21:13-21.

26. The 5 key takeaways on the new heart transplant allocation guidelines. Available online: https:/www.advisory.com/ research/cardiovascular-roundtable/cardiovascularrounds/2018/10/5-takeaways

27. 2018 Revised UNOS Heart Allocation System Guide. Available online: https://syncardia.com/unos-guide/

28. Cogswell R, John R, Estep JD, et al. An early investigation of outcomes with the new 2018 donor heart allocation system in the United States. J Hear Lung Transplant 2020;39:1-4.

29. Copeland JG, Smith RG, Arabia FA, et al. Cardiac replacement with a total artificial heart as a bridge to transplantation. N Engl J Med 2004;351:859-67. 
Table S1 Newcastle-Ottawa Scale (NOS) scoring system to asses risk of bias for the studies included

\begin{tabular}{|c|c|c|c|c|c|c|c|c|c|}
\hline Study name & $\begin{array}{l}\text { Representatives } \\
\text { of the exposed } \\
\text { cohort }\end{array}$ & $\begin{array}{l}\text { Selection of the } \\
\text { non-exposed } \\
\text { cohort }\end{array}$ & $\begin{array}{l}\text { Ascertainment } \\
\text { of exposure }\end{array}$ & $\begin{array}{l}\text { Outcome of } \\
\text { interest Was } \\
\text { not present at } \\
\text { start of study }\end{array}$ & $\begin{array}{l}\text { Comparability } \\
\text { of cohorts on } \\
\text { the bases of the } \\
\text { design or analysis }\end{array}$ & $\begin{array}{l}\text { Assessment } \\
\text { of outcome }\end{array}$ & $\begin{array}{l}\text { Was follow-up } \\
\text { long enough } \\
\text { for outcome } \\
\text { to occur }\end{array}$ & $\begin{array}{l}\text { Adequacy } \\
\text { of follow-up }\end{array}$ & $\begin{array}{l}\text { Total quality } \\
\text { score } \\
\text { (out of 9) }\end{array}$ \\
\hline $\begin{array}{l}\text { Discontinuation of } \\
\text { HeartWare RVAD support } \\
\text { without device removal in } \\
\text { chronic BIVAD patients }\end{array}$ & 1 & 0 & 1 & 1 & 0 & 1 & 1 & 1 & 6 \\
\hline $\begin{array}{l}\text { Surgical Considerations } \\
\text { and Challenges for Bilateral } \\
\text { Continuous-Flow Durable } \\
\text { Device Implantation }\end{array}$ & 0 & 0 & 1 & 1 & 0 & 1 & 1 & 1 & 5 \\
\hline $\begin{array}{l}\text { Long-term biventricular } \\
\text { HeartWare ventricular } \\
\text { assist device support- } \\
\text { Case series of right atrial } \\
\text { and right ventricular } \\
\text { implantation outcomes }\end{array}$ & 1 & 0 & 1 & 1 & 0 & 1 & 1 & 1 & 6 \\
\hline $\begin{array}{l}\text { Durable Biventricular } \\
\text { Support Using Right } \\
\text { Atrial Placement of the } \\
\text { HeartWare HVAD }\end{array}$ & 1 & 0 & 1 & 1 & 0 & 1 & 1 & 1 & 6 \\
\hline $\begin{array}{l}\text { Liver failure in total artificial } \\
\text { heart therapy }\end{array}$ & 1 & 0 & 1 & 1 & 0 & 1 & 0 & 0 & 4 \\
\hline $\begin{array}{l}\text { CardioWest total artificial } \\
\text { heart: Bad Oeynhausen } \\
\text { experience }\end{array}$ & 1 & 0 & 1 & 1 & 0 & 1 & 1 & 1 & 6 \\
\hline $\begin{array}{l}\text { Survival after biventricular } \\
\text { mechanical circulatory } \\
\text { support: Does the type of } \\
\text { device matter? }\end{array}$ & 1 & 0 & 1 & 1 & 0 & 1 & 1 & 1 & 6 \\
\hline $\begin{array}{l}\text { CardioWest (Jarvik) total } \\
\text { artificial heart: a single- } \\
\text { center experience with } 42 \\
\text { patients }\end{array}$ & 1 & 0 & 1 & 1 & 0 & 1 & 1 & 1 & 6 \\
\hline $\begin{array}{l}\text { Bridge to transplantation } \\
\text { with the Jarvik-7 } \\
\text { (CardioWest) total artificial } \\
\text { heart: a single-center } 15- \\
\text { year experience }\end{array}$ & 1 & 0 & 1 & 1 & 0 & 1 & 1 & 1 & 6 \\
\hline $\begin{array}{l}\text { Experience with the } \\
\text { SynCardia total artificial } \\
\text { heart in a Canadian centre }\end{array}$ & 1 & 0 & 1 & 1 & 0 & 1 & 1 & 1 & 6 \\
\hline $\begin{array}{l}\text { Experience with more than } \\
100 \text { total artificial heart } \\
\text { implants }\end{array}$ & 1 & 0 & 1 & 1 & 0 & 1 & 1 & 1 & 6 \\
\hline $\begin{array}{l}\text { Clinical indications for } \\
\text { implantation of the total } \\
\text { artificial heart }\end{array}$ & 1 & 0 & 1 & 1 & 0 & 1 & 1 & 1 & 6 \\
\hline
\end{tabular}


Table S2 Characteristics of studies included in the meta-analysis

\begin{tabular}{|c|c|c|c|c|c|c|c|c|}
\hline Title & Authors & $\begin{array}{l}\text { Year } \\
\text { published }\end{array}$ & Institution & Journal & Study & $\begin{array}{l}\text { Study } \\
\text { date(s) }\end{array}$ & $\begin{array}{l}\text { Total } \\
\text { patients }\end{array}$ & $\begin{array}{l}\text { New-Castle } \\
\text { Ottawa } \\
\text { Scale Score }\end{array}$ \\
\hline $\begin{array}{l}\text { Discontinuation of HeartWare } \\
\text { RVAD support without device } \\
\text { removal in chronic BIVAD } \\
\text { patients }\end{array}$ & Potapov et al. & 2012 & $\begin{array}{l}\text { German Heart Institute, } \\
\text { Berlin }\end{array}$ & ASAIO J & $\begin{array}{l}\text { Prospective } \\
\text { study }\end{array}$ & 2009 & 10 & 6 \\
\hline $\begin{array}{l}\text { Surgical Considerations } \\
\text { and Challenges for Bilateral } \\
\text { Continuous-Flow Durable } \\
\text { Device Implantation }\end{array}$ & Maltais et al. & 2016 & Mayo Clinic, Rochester & ASAIO J & $\begin{array}{l}\text { Retrospective } \\
\text { study }\end{array}$ & 2013-2014 & 4 & 5 \\
\hline $\begin{array}{l}\text { Long-term biventricular } \\
\text { HeartWare ventricular assist } \\
\text { device support-Case } \\
\text { series of right atrial and } \\
\text { right ventricular implantation } \\
\text { outcomes }\end{array}$ & Shehab et al. & 2016 & St. Vincent's Hospital & $J H L T$ & Case series & 2011-2014 & 13 & 6 \\
\hline $\begin{array}{l}\text { Durable Biventricular Support } \\
\text { Using Right Atrial Placement } \\
\text { of the HeartWare HVAD }\end{array}$ & Tran et al. & 2017 & $\begin{array}{l}\text { University of California } \\
\text { San Diego }\end{array}$ & ASAIO J & $\begin{array}{l}\text { Retrospective } \\
\text { study }\end{array}$ & 2014-2016 & 11 & 6 \\
\hline $\begin{array}{l}\text { Liver failure in total artificial } \\
\text { heart therapy }\end{array}$ & Dimitriou et al. & 2016 & $\begin{array}{l}\text { Heart and Vascular Center } \\
\text { Duisburg }\end{array}$ & $\begin{array}{l}J \text { Thorac } \\
\text { Dis }\end{array}$ & $\begin{array}{l}\text { Retrospective } \\
\text { study }\end{array}$ & 2011-2015 & 31 & 4 \\
\hline $\begin{array}{l}\text { CardioWest total artificial } \\
\text { heart: Bad Oeynhausen } \\
\text { experience }\end{array}$ & $\begin{array}{l}\text { El-Banayosy } \\
\text { et al. }\end{array}$ & 2005 & $\begin{array}{l}\text { Ruhr University Bochum, } \\
\text { Bad Oeynhausen, } \\
\text { Germany }\end{array}$ & $J H L T$ & $\begin{array}{l}\text { Retrospective } \\
\text { study }\end{array}$ & 2001-2003 & 42 & 6 \\
\hline $\begin{array}{l}\text { Survival after biventricular } \\
\text { mechanical circulatory } \\
\text { support: Does the type of } \\
\text { device matter? }\end{array}$ & Kirsch et al. & 2012 & $\begin{array}{l}\text { Hôpital La Pitié- } \\
\text { Salpétrière, Nouvel } \\
\text { Hôpital Civil }\end{array}$ & $J H L T$ & Retrospective & 2000-2010 & 90 & 6 \\
\hline $\begin{array}{l}\text { CardioWest (Jarvik) total } \\
\text { artificial heart: a single-center } \\
\text { experience with } 42 \text { patients }\end{array}$ & Roussel et al. & 2009 & $\begin{array}{l}\text { Institut du Thorax, Nantes } \\
\text { Hospital University, } \\
\text { Nantes, France }\end{array}$ & $\begin{array}{l}\text { Ann Thorac } \\
\text { Surg }\end{array}$ & $\begin{array}{l}\text { Retrospective } \\
\text { study }\end{array}$ & 1990-2006 & 42 & 6 \\
\hline $\begin{array}{l}\text { Bridge to transplantation with } \\
\text { the Jarvik-7 (CardioWest) } \\
\text { total artificial heart: a single- } \\
\text { center } 15 \text {-year experience }\end{array}$ & Leprince et al. & 2003 & $\begin{array}{l}\text { La Pitié-Salpétrière } \\
\text { Hospital France }\end{array}$ & $J H L T$ & $\begin{array}{l}\text { Retrospective } \\
\text { study }\end{array}$ & 1986-2001 & 127 & 6 \\
\hline $\begin{array}{l}\text { Experience with the } \\
\text { SynCardia total artificial heart } \\
\text { in a Canadian centre }\end{array}$ & Nguyen et al. & 2017 & Montreal Heart Institute & Can J Surg & $\begin{array}{l}\text { Retrospective } \\
\text { study }\end{array}$ & 2004-2016 & 13 & 6 \\
\hline $\begin{array}{l}\text { Experience with more than } \\
100 \text { total artificial heart } \\
\text { implants }\end{array}$ & Copeland et al. & 2012 & University of Arizona & $\begin{array}{l}\text { J Thorac } \\
\text { Cardiovasc } \\
\text { Surg }\end{array}$ & $\begin{array}{l}\text { Retrospective } \\
\text { study }\end{array}$ & 1993-2009 & 101 & 6 \\
\hline $\begin{array}{l}\text { Clinical indications for } \\
\text { implantation of the total } \\
\text { artificial heart }\end{array}$ & Thanavaro et al. & 2014 & $\begin{array}{l}\text { Virginia Commonwealth } \\
\text { University }\end{array}$ & ASAIO J & $\begin{array}{l}\text { Retrospective } \\
\text { study }\end{array}$ & 2006-2012 & 66 & 6 \\
\hline
\end{tabular}

